\title{
Impact of previous cardiac surgery with sternotomy on clinical outcomes and quality of life after transcatheter aortic valve implantation for severe aortic stenosis
}

\author{
Tomasz Tokarek ${ }^{1}$, Artur Dziewierz ${ }^{2}$, Maciej Bagienski ${ }^{2}$, Lukasz Rzeszutko², \\ Danuta Sorysz², Pawel Kleczynski², Dariusz Dudek ${ }^{1}$ \\ 'Department of Interventional Cardiology, Institute of Cardiology, Jagiellonian University, Medical College, Krakow, Poland \\ ${ }^{2} 2^{\text {nd }}$ Department of Cardiology, Institute of Cardiology, Jagiellonian University, Medical College, Krakow, Poland
}

\begin{abstract}
Background: Transcatheter aortic valve implantation (TAVI) has evolved as an effective treatment in patients with symptomatic severe aortic stenosis (AS) and increased operative risk. Data on the influence of previous sternotomy on the risk of TAVI are limited.

Aim: We sought to investigate the effect of previous cardiac surgery with sternotomy on clinical outcomes and quality of life (QoL) after TAVI.

Methods: The study included 148 consecutive patients with symptomatic severe AS, who underwent TAVI. Baseline characteristics, procedural and long-term clinical outcomes, and QoL assessment with the EQ-5D-3L questionnaire were compared between patients with and without previous sternotomy.

Results: Patients with previous sternotomy (23.0\% of the population) were younger and more often male, had higher rate of previous myocardial infarction (MI; 26 [22.8\%] vs. 22 [64.7\%], $\mathrm{p}=0.001)$, and lower median left ventricular ejection fraction $(60.0 \%$ [50.0-65.0] vs. 50.0\% [42.0-60.0], $p=0.004)$. Periprocedural risk measured with the Logistic Euroscore and the Society of Thoracic Surgeons scale was comparable in both groups. There were no differences in 30-day and 12-month all-cause mortality between the groups with and without sternotomy (10 [8.8\%] vs. 2 [5.9\%], $p=0.7$; odds ratio [OR] adjusted for age/sex/previous $\mathrm{MI}, 0.56,95 \%$ confidence interval $[\mathrm{Cl}]$ 0.10-3.29; for 12-month mortality adjusted OR $0.19,95 \% \mathrm{Cl}$ 0.04-0.99). At the longest available follow-up, mortality was higher in patients without sternotomy (30 [26.3\%] vs. 3 [8.8\%], $\mathrm{p}=0.03$; adjusted OR $0.10,95 \% \mathrm{Cl} 0.02-0.42$ ). Similar rates of other complications after TAVI were noted. No differences in the EQ-5D-3L questionnaire at baseline and 12-month follow-up were confirmed.

Conclusions: TAVI seems to be a safe and effective technique for the treatment of severe AS in patients with previous cardiac surgery.
\end{abstract}

Key words: transcatheter aortic valve replacement, aortic valve disease, high-risk patients, registry

Kardiol Pol 2018; 76, 5: 838-844

\section{INTRODUCTION}

Transcatheter aortic valve implantation (TAVI) has been demonstrated as an effective treatment in patients with symptomatic severe aortic stenosis (AS) and increased operative risk [1-3]. An improvement in clinical outcomes and quality of life (QoL) after TAVI in long-term follow-up was confirmed by several studies [4-8]. Patients with previous cardiac surgery are considered to be at increased perioperative risk for redo cardiac operations $[9,10]$. Previous cardiac surgery imposes additional risks on patients undergoing median sternotomy [11-13]. Furthermore, patients with a history of coronary artery bypass grafting (CABG) may face an additional risk of damage to the

\section{Address for correspondence:}

Pawel Kleczynski, MD, PhD, $2^{\text {nd }}$ Department of Cardiology, Institute of Cardiology, Jagiellonian University, Medical College, ul. Kopernika 17, 31-501 Kraków, Poland, tel: + 4812 4247181, fax: + 4812 4247184, e-mail: kleczu@interia.pl

Received: 27.07.2017 Accepted: 04.12.2017 Available as AoP: 12.01.2018

Kardiologia Polska Copyright (C) Polish Cardiac Society 2018 
graft, which is associated with worse periprocedural outcomes [11-13]. Nowadays, these patients constitute a considerable portion of those with severe AS referred for TAVI due to the minimally invasive nature of this approach. However, outcomes of patients with previous sternotomy undergoing TAVI are still under investigation. Thus, we sought to investigate the impact of previous cardiac surgery with sternotomy on clinical outcomes and QoL after TAVI.

\section{METHODS}

A complete description was reported previously [14]. We enrolled 148 consecutive patients who underwent TAVI. All the patients had symptomatic severe AS and high periprocedural risk or contraindications for surgical aortic valve replacement. The eligibility for TAVI was based on the consensus of the multidisciplinary Heart Team. Baseline characteristics and procedural data were collected prospectively. TAVI procedures were performed using Edwards Sapien, Edwards Sapien XT, Edwards Sapien 3 (Edwards Lifesciences, Irvine, CA, USA), Medtronic CoreValve/Evolut R (Medtronic, Inc., Minneapolis, MN, USA), JenaValve (JenaValve Technology, Munich, Germany), Lotus (Boston Scientific), and New Valve Technology transcatheter heart valves. The decision about the type and size of the valve as well as the access route was at the discretion of the Heart Team and treating physicians. Procedures were performed under general anaesthesia or local anaesthesia with sedation. Clinical endpoints of the study included all-cause mortality at 30 days and every six months up to maximal available follow-up and complications rate up to 12 months. QoL was assessed with the validated Polish version of the EQ-5D-3L questionnaire at baseline and 12 months after TAVI. The visual analogue scale (VAS) score, which is a part of the EQ-5D-3L, was also assessed. Outcome endpoints were in accordance with Valve Academic Research Consortium definitions (VARC-2) [15]. For this analysis, patients were divided into two groups according to the presence of cardiac surgery with sternotomy. Written informed consent was collected from each patient included in the study. The study was approved by the institutional ethical board and was conducted according to the ethical guidelines of the 1975 Declaration of Helsinki with later amendments.

\section{Statistical analysis}

Results are presented as number of patients (percentage) or median (interquartile range [IQR]), where applicable. Differences between groups were tested using the $\chi^{2}$ test and Fisher's exact test for dichotomous variables and the Mann-Whitney U-test for continuous variables. Changes in EQ-5D-3L questionnaire between baseline and follow-up evaluations were analysed using McNemar's test. The relationship between baseline and follow-up responses in the VAS score were analysed with a Wilcoxon signed-rank test. Comparisons of baseline and 12-month outcomes were calculated excluding unpaired results. The difference in mortality between patients with and without previous sternotomy during follow-up was assessed with Kaplan-Meier method. In addition, differences in outcomes were presented as odds ratios (ORs) adjusted for age/sex/previous myocardial infarction (MI) with 95\% confidence intervals (Cls). Multivariable Cox regression model was constructed to identify significant predictors of 12-month mortality. All baseline characteristics and procedural data were considered and forward selection with a probability value for covariates to enter the model of 0.05 was used. Results were presented as hazard ratios (HRs) with $95 \% \mathrm{Cl}$. All tests were two-tailed, and a p-value of $<0.05$ was considered statistically significant. All statistical analyses were performed using SPSS 15.0 (SPSS, Inc., Chicago, IL, USA).

\section{RESULTS}

Of the 148 consecutive patients undergoing TAVI, previous cardiac surgery with sternotomy was confirmed in $34(23.0 \%)$, and previous CABG was the reason for sternotomy in $28(82.4 \%)$ of these 34 patients with a history of cardiac surgery. Patients with previous sternotomy were younger and were more often male, with a higher rate of previous MI (26 [22.8\%] vs. 22 [64.7\%]; $p=0.001$; Table 1). Similar rates of other comorbidities were reported in both groups. Furthermore, no difference in periprocedural risk measured with Logistic Euroscore and the Society of Thoracic Surgeons (STS) was noted. Procedural details are presented in Table 2. A comparable length of hospital stay was observed in patients with and without a history of sternotomy (10.0 [8.5-12.0] vs. 10.0 [8.0-13.5] days; $p=0.80$ ). No differences between groups in all components of the EQ-5D-3L questionnaire were confirmed at baseline and 12 months after TAVI (Fig. 1). The median VAS at baseline (40.0 [30.0-50.0] vs. 41.0 [40.0-70.0]; $p=0.20)$ and 12 months after TAVI (70.0 [60.0-80.0] vs. 70.0 [62.5-80.0]; $p=0.60$ ) was comparable between groups. Similarly, no difference in VAS change during follow-up was noted between groups (30.0 [15.0-40.0] vs. 17.5 [10.0-30.0]; $p=0.07$ ). Lower median of left ventricular ejection fraction before $(60.0 \%$ [50.0-65.0] vs. 50.0\% [42.0-60.0], p = 0.004) and after TAVI procedure $(49.0 \%$ [45.0-55.0] vs. $45.0 \%$ [35.0-50.0], $\mathrm{p}=0.05$ ) was confirmed in patients with previous sternotomy (Table 3). Median follow-up of all patients was 13.3 (6.0-31.1) months. There were no differences in 30-day and 12-month all-cause mortality between groups (sternotomy [-] vs. sternotomy [+]: 10 [8.8\%] vs. 2 [5.9\%], $p=0.70 ; 20$ [17.5\%] vs. $2[5.9 \%] ; p=0.10$, respectively). Also, no influence of previous sternotomy on the risk of death was confirmed after adjustment for age/sex/previous MI (for 30-day mortality adjusted OR 0.56, 95\% Cl 0.10-3.29; for 12-month mortality adjusted OR 0.19, 95\% Cl 0.04-0.99). However, at the longest available follow-up mortality was higher in patients without previous sternotomy (30 [26.3\%] vs. 3 [8.8\%]; $p=0.03$, 
Table 1. Baseline clinical characteristics

\begin{tabular}{|c|c|c|c|c|}
\hline & $\begin{array}{l}\text { All patients } \\
(n=148)\end{array}$ & $\begin{array}{l}\text { Previous sternotomy } \\
\qquad(-)(n=114)\end{array}$ & $\begin{array}{l}\text { Previous sternotomy } \\
\qquad(+)(n=34)\end{array}$ & p \\
\hline Age [years] & $82.0(77.0-85.0)$ & $83.0(79.0-85.0)$ & $78.0(73.0-82.0)$ & 0.001 \\
\hline Age $\geq 80$ years & $92(62.2 \%)$ & $81(71.1 \%)$ & $11(32.4 \%)$ & 0.001 \\
\hline Men & $56(37.8 \%)$ & $36(31.6 \%)$ & $20(58.8 \%)$ & 0.004 \\
\hline Body mass index $\left[\mathrm{kg} / \mathrm{m}^{2}\right]$ & $27.2(25.2-30.6)$ & $27.4(25.4-30.6)$ & $27.0(24.3-29.9)$ & 0.3 \\
\hline eGFR $\left[\mathrm{mL} / \mathrm{min} / 1.73 \mathrm{~m}^{2}\right]$ & $56.5(40.0-72.0)$ & $54.0(40.0-71.0)$ & $62.0(40.5-75.4)$ & 0.5 \\
\hline NYHA class: & & & & 0.4 \\
\hline I & $0(0.0 \%)$ & $0(0.0 \%)$ & $0(0.0 \%)$ & \\
\hline$\|$ & $41(27.7 \%)$ & $29(25.4 \%)$ & $12(35.3 \%)$ & \\
\hline III & $97(65.5 \%)$ & $76(66.7 \%)$ & $21(61.8 \%)$ & \\
\hline IV & $10(6.8 \%)$ & $9(7.9 \%)$ & $1(2.9 \%)$ & \\
\hline Arterial hypertension & $139(93.9 \%)$ & 107 (93.9\%) & $32(94.1 \%)$ & 0.99 \\
\hline Diabetes mellitus & 48 (32.4\%) & $41(36.0 \%)$ & $7(20.6 \%)$ & 0.1 \\
\hline Atrial fibrillation & $52(35.1 \%)$ & $44(38.6 \%)$ & $8(23.5 \%)$ & 0.1 \\
\hline Previous Ml & $48(32.4 \%)$ & $26(22.8 \%)$ & $22(64.7 \%)$ & 0.001 \\
\hline Previous PCI & $43(29.1 \%)$ & 35 (30.7\%) & $8(23.5 \%)$ & 0.4 \\
\hline Previous CABG & $28(18.9 \%)$ & $0(0.0 \%)$ & $28(82.4 \%)$ & 0.001 \\
\hline Coronary chronic total occlusion & $14(9.5 \%)$ & $12(10.5 \%)$ & $2(5.9 \%)$ & 0.5 \\
\hline Incomplete revascularisation & $22(14.9 \%)$ & $18(15.8 \%)$ & $4(11.8 \%)$ & 0.6 \\
\hline COPD & $19(12.8 \%)$ & $16(14.0 \%)$ & $3(8.8 \%)$ & 0.6 \\
\hline Stroke/TIA & $17(11.5 \%)$ & $13(11.4 \%)$ & $4(11.8 \%)$ & 0.99 \\
\hline Pacemaker & $17(11.5 \%)$ & $15(13.2 \%)$ & $2(5.9 \%)$ & 0.4 \\
\hline Logistic Euroscore I [\%] & $14.5(10.0-22.7)$ & $13.5(10.0-21.0)$ & $18.8(10.0-27.0)$ & 0.1 \\
\hline Society of Thoracic Surgeons score [\%] & $6.2(4.0-17.3)$ & $6.0(4.0-17.5)$ & $8.0(5.0-16.0)$ & 0.7 \\
\hline
\end{tabular}

Data are shown as median and interquartile range (IQR) or number and percentage. CABG — coronary artery bypass graft; COPD — chronic obstructive pulmonary disease; eGFR — estimated glomerular filtration rate; MI — myocardial infarction; NYHA — New York Heart Association; $\mathrm{PCl}$ - percutaneous coronary intervention; TIA — transient ischaemic attack

adjusted OR 0.10, 95\% Cl 0.02-0.42; Fig. 2). Interestingly, the difference in mortality was confirmed only for patients treated with non-femoral access (10 [45.5\%] vs. 0 [0.0\%]; $\mathrm{p}=0.030$ ) with no impact on mortality in patients from the femoral access group (20 [21.7\%] vs. 3 [12.0\%]; $p=0.40$ ). Rates of in-hospital grade 3 acute kidney injury (sternotomy [-] vs. sternotomy [+]: 7 [6.1\%] vs. 1 [2.9\%], p = 0.70; adjusted OR $0.63,95 \% \mathrm{Cl} 0.06-6.74)$, bleeding complications (sternotomy [-] vs. sternotomy [+]: 41 [36.0\%] vs. 8 [23.5\%]; $p=0.20$; adjusted OR $0.65,95 \% \mathrm{Cl} 0.24-1.77)$, and blood transfusions (sternotomy [-] vs. sternotomy [+]: 35 [30.7\%] vs. 9 [26.5\%], $\mathrm{p}=0.60$; adjusted OR 1.06, 95\% Cl 0.39-2.90) were comparable between groups. Similarly, no differences in stroke/transient ischaemic attack (TIA; sternotomy [-] vs. sternotomy [+]: 9 [5.3\%] vs. 4 [11.8\%], $p=0.20$; adjusted OR 1.94, 95\% Cl 0.39-9.59), MI (sternotomy [-] vs. sternotomy [+]: 3 [2.6\%] vs. 1 [2.9\%], p = 0.99; adjusted OR 0.08, 95\% $\mathrm{Cl}$ 0.01-2.10), need for permanent pacemaker stimulation (sternotomy [-] vs. sternotomy [+]: 20 [17.5\%] vs. 4 [11.8\%], $\mathrm{p}=0.40$; adjusted $\mathrm{OR} 0.89,95 \% \mathrm{Cl} 0.24-3.33)$, and new-onset atrial fibrillation (sternotomy [-] vs. sternotomy [+]: 9 [7.9\%] vs. 1 [2.9\%], p = 0.50; adjusted OR 0.17, 95\% Cl 0.02-1.69) were reported during 12-month follow-up. Previous cardiac surgery with sternotomy was not identified as an independent predictor of mortality in multivariable Cox regression analysis. Incomplete coronary revascularisation (HR 5.45, 95\% Cl 2.38-12.52; $\mathrm{p}=0.001)$, estimated glomerular filtration rate (HR 0.96 per $1 \mathrm{~mL} / \mathrm{min} / 1.73 \mathrm{~m}^{2}$ increase, $95 \% \mathrm{Cl}$ 0.94-0.98; $p=0.001$ ), and previous stroke/TIA (HR 2.86, $95 \% \mathrm{Cl} 1.17-7.00 ; \mathrm{p}=0.02$ ) were identified as the only independent determinants of death.

\section{DISCUSSION}

The results of this study suggest no impact of previous cardiac surgery with sternotomy on the risk of adverse events in patients undergoing TAVI as compared with patients with no 
Table 2. Procedural data

\begin{tabular}{|c|c|c|c|c|}
\hline & $\begin{array}{l}\text { All patients } \\
(n=148)\end{array}$ & $\begin{array}{l}\text { Previous sternotomy } \\
\qquad(-)(n=114)\end{array}$ & $\begin{array}{l}\text { Previous sternotomy } \\
\qquad(+)(n=34)\end{array}$ & $\mathbf{p}$ \\
\hline Access type: & & & & 0.5 \\
\hline Transfemoral & $117(79.1 \%)$ & $92(80.7 \%)$ & $25(73.5 \%)$ & \\
\hline Transapical & $28(18.9 \%)$ & $20(17.5 \%)$ & $8(23.5 \%)$ & \\
\hline Transaortic & $2(1.4 \%)$ & $1(0.9 \%)$ & $1(2.9 \%)$ & \\
\hline Subclavian & $1(0.7 \%)$ & $1(0.9 \%)$ & $0(0.0 \%)$ & \\
\hline Device implanted: & & & & 0.1 \\
\hline Corevalve/Evolut R & $29(19.6 \%)$ & $16(14.0 \%)$ & $13(38.2 \%)$ & \\
\hline Edwards Sapien & $95(64.2 \%)$ & $78(68.4 \%)$ & $17(50.0 \%)$ & \\
\hline Jena & $10(6.8 \%)$ & $8(7.0 \%)$ & $2(5.9 \%)$ & \\
\hline Lotus & $9(6.1 \%)$ & $8(7.0 \%)$ & $1(2.9 \%)$ & \\
\hline NVT & $5(3.4 \%)$ & $4(3.5 \%)$ & $1(2.9 \%)$ & \\
\hline Prosthesis size: & & & & 0.1 \\
\hline $23 \mathrm{~mm}$ & $30(20.3 \%)$ & $22(19.3 \%)$ & $8(23.5 \%)$ & \\
\hline $25 \mathrm{~mm}$ & $8(5.4 \%)$ & $8(7.0 \%)$ & $0(0.0 \%)$ & \\
\hline $26 \mathrm{~mm}$ & $56(37.8 \%)$ & $45(39.5 \%)$ & $11(32.4 \%)$ & \\
\hline $27 \mathrm{~mm}$ & $8(5.4 \%)$ & $7(6.1 \%)$ & $1(2.9 \%)$ & \\
\hline $29 \mathrm{~mm}$ & $38(25.7 \%)$ & $29(25.4 \%)$ & $9(26.5 \%)$ & \\
\hline $31 \mathrm{~mm}$ & $8(5.4 \%)$ & $3(2.6 \%)$ & $5(14.7 \%)$ & \\
\hline Prosthesis size [mm] & $26.0(25.0-29.0)$ & $26.0(25.0-29.0)$ & $26.0(26.0-29.0)$ & 0.2 \\
\hline Radiation dose [mGy] & $721.0(632.5-827.5)$ & $715.0(632.0-823.0)$ & $721.0(673.0-834.0)$ & 0.9 \\
\hline Contrast medium load [mL] & $75.0(50.0-137.5)$ & $75.0(50.0-100.0)$ & $75.0(50.0-150.0)$ & 0.8 \\
\hline Fluoroscopy time [min] & $13.0(12.0-15.0)$ & $13.0(12.0-15.0)$ & $13.0(11.0-14.0)$ & 0.5 \\
\hline
\end{tabular}

Data are shown as median and interquartile range (IQR) or number and percentage. NVT — New Valve Technology

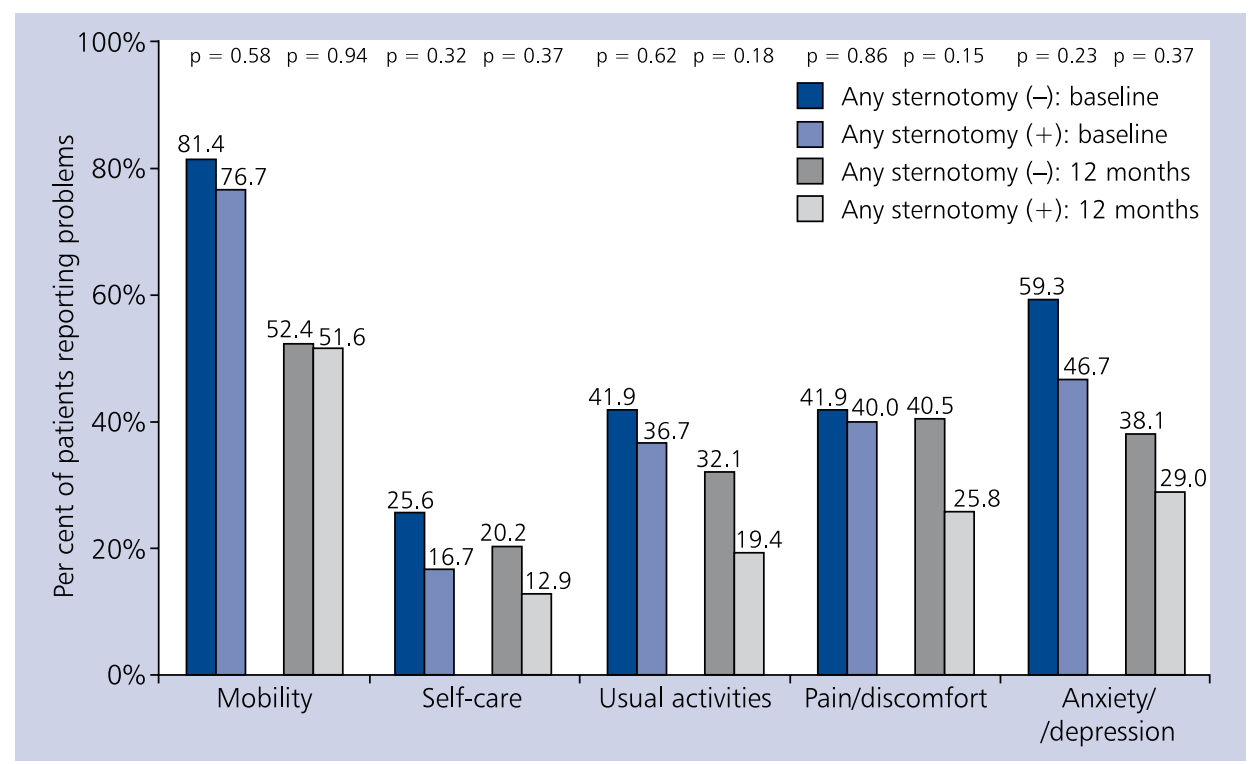

Figure 1. Proportions of patients reporting either "some problems" or "extreme problems" for each category of the EQ-5D-3L at baseline and 12 months 
Table 3. Echocardiographic data before and after transcatheter aortic valve implantation

\begin{tabular}{|c|c|c|c|c|}
\hline & $\begin{array}{l}\text { All patients } \\
(n=148)\end{array}$ & $\begin{array}{l}\text { Previous sternotomy } \\
\qquad(-)(n=114)\end{array}$ & $\begin{array}{l}\text { Previous sternotomy } \\
\qquad(+)(n=34)\end{array}$ & p \\
\hline TG max before TAVI [mmHg] & $86.0(69.0-103.0)$ & $86.0(69.0-104.0)$ & $84.0(71.0-98.0)$ & 0.5 \\
\hline TG mean before TAVI [mmHg] & $50.0(42.0-63.0)$ & $50.0(41.0-64.0)$ & $49.5(42.0-55.7)$ & 0.5 \\
\hline AVA before TAVI $\left[\mathrm{cm}^{2}\right]$ & $0.7(0.6-0.8)$ & $0.7(0.6-0.8)$ & $0.8(0.5-0.9)$ & 0.6 \\
\hline LVEF before TAVI [\%] & $60.0(50.0-65.0)$ & $60.0(50.0-65.0)$ & $50.0(42.0-60.0)$ & 0.004 \\
\hline AR before: & & & & 0.5 \\
\hline 0 & $48(32.4 \%)$ & $40(35.1 \%)$ & $8(23.5 \%)$ & \\
\hline 1 & $75(50.7 \%)$ & $56(49.1 \%)$ & $19(55.9 \%)$ & \\
\hline 2 & $20(13.5 \%)$ & $15(13.2 \%)$ & $5(14.7 \%)$ & \\
\hline 3 & $5(3.4 \%)$ & $3(2.6 \%)$ & $2(5.9 \%)$ & \\
\hline TG max after TAVI [mmHg] & $13.0(10.0-19.0)$ & $13.5(10.1-19.0)$ & $13.0(8.0-18.0)$ & 0.2 \\
\hline TG mean after TAVI [mmHg] & $7.4(5.1-10.0)$ & $8.0(6.0-10.5)$ & $7.0(5.0-9.0)$ & 0.3 \\
\hline LVEF after TAVI [\%] & $48.0(41.0-55.0)$ & $49.0(45.0-55.0)$ & $45.0(35.0-50.0)$ & 0.05 \\
\hline AR after TAVI: & & & & 0.4 \\
\hline 0 & $84(56.8 \%)$ & $64(56.1 \%)$ & $20(58.8 \%)$ & \\
\hline 1 & $55(37.2 \%)$ & $42(36.8 \%)$ & $13(38.2 \%)$ & \\
\hline 2 & $7(4.7 \%)$ & $7(6.1 \%)$ & $0(0.0 \%)$ & \\
\hline 3 & $2(1.4 \%)$ & $1(0.9 \%)$ & 1 (2.9\%) & \\
\hline
\end{tabular}

Data are shown as median and interquartile range (IQR) or number and percentage. AR — aortic regurgitation; AVA — aortic valve area; LVEF — left ventricular ejection fraction; TAVI — transcatheter aortic valve implantation; TG — transvalvular gradient

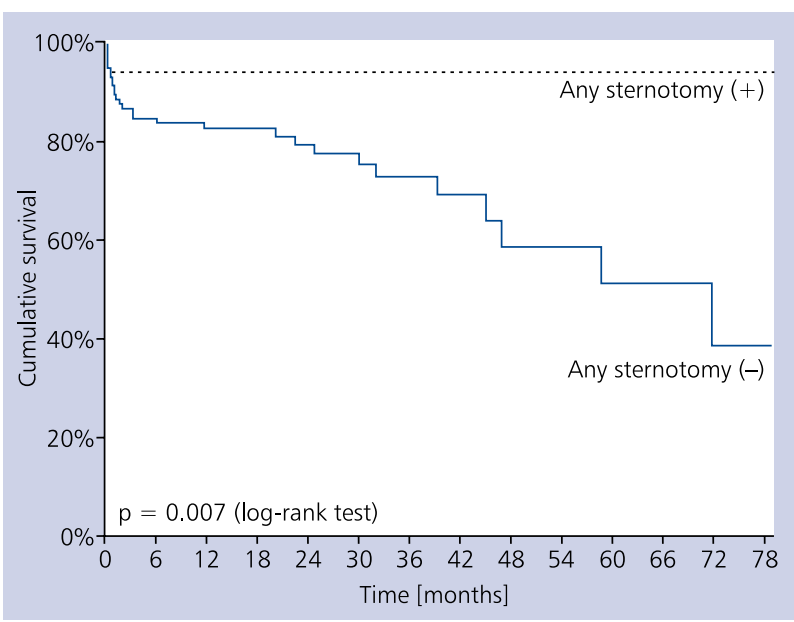

Figure 2. Kaplan-Meier curves for survival after transcatheter valve implantation stratified by previous sternotomy (without previous sternotomy — solid line; with previous sternotomy — dotted line)

history of chest opening. These results were maintained after the adjustment for age, sex, and previous MI. No differences in the results of QoL assessment were observed between groups.

Previous sternotomy was not identified as an independent predictor of all-cause long-term mortality. Observed higher long-term mortality in patients without previous sternotomy might be partially related to some differences in age and baseline risk profile between groups. These data stay in line with results from most recent studies reporting no influence of prior cardiac surgery on survival rate after TAVI. A recent large meta-analysis has reported no significant difference in 30-day and one-year all-cause mortality between patients undergoing TAVI with and without a history of previous cardiac surgery with sternotomy (risk ratio 0.95, 95\% Cl 0.82-1.09, $\mathrm{p}=0.55$; risk ratio $0.94,95 \% \mathrm{Cl} 0.86-1.02, \mathrm{p}=0.48$, respectively) [16]. In addition, results of subgroup analysis including only patients with a history of CABG also did not show differences between those groups [16]. Interestingly, the rate of major vascular complications was marginally lower in patients with previous cardiac surgery, but the calculation was not robust because the result lost significance in sensitivity analysis [16]. Also, the risk of acute $\mathrm{MI}$ was significantly higher in patients with prior sternotomy, but a higher prevalence of coronary artery disease (CAD) and diabetes mellitus in the previous cardiac surgery group was the probable reason for this worse outcome [16]. However, most of the included studies were non-randomised or were post hoc analyses of randomised trials; thus, it may have limited the external validity of the analysis. In our study, no difference in the rate of all complications was confirmed. Several studies reported comparable clinical outcomes between patients with and without a history of prior cardiac surgery with sternotomy [17-21]. However, Ducrocq et al. [22] 
reported better survival in patients with previous CABG undergoing TAVI. Multivariate analysis identified a history of CABG as an independent predictor of better two-year survival [22]. Conversely, this study also confirmed that transapical approach (TA) is a predictor of two-year mortality [22]. On the other hand, these results may be related to the residual bias in an observational nature of this analysis. In our study, we did not take into account variables such as the type of valve and type of vascular approach, which could affect clinical outcomes. Some would argue that TA may be challenging in patients with previous sternotomy undergoing TAVI. Few studies have assessed the outcomes of TA use in TAVI patients with prior cardiac operations. The results were similar in patients with and without a history of chest opening [17, 23-26]. These data suggested that both TA and transfemoral (TF) TAVI are reasonable options in patients with severe AS and previous cardiac operation. In patients with a history of previous cardiac surgery with sternotomy, the potential superiority of TAVI is linked to the minimally invasive nature of the procedure [17]. Small mediastinal dissection (in TA-TAVI and transaortic approach) or no incision at all (TF-TAVI and trans-subclavian approach) reduce potential risk related to all complications associated with chest reopening [17]. Furthermore, no need for extracorporeal circulation provides an additional advantage [17]. In contrast, TAVI does not eliminate the fact that patients with previous CABG have a history of significant CAD, which by itself may result in additive risk [17]. In our study, despite a higher rate of previous $\mathrm{MI}$ in patients with a history of sternotomy, the adverse outcomes were not different in comparison with patients with no prior cardiac surgery. The vast majority of redo patients had previous CABG operations $(82.4 \%)$, but the incidence of perioperative and long-term $\mathrm{MI}$ was low. This could be explained by the potential protective function of the patent grafts. Furthermore, all patients underwent diagnostic angiography before they were scheduled for TAVI to exclude progression of CAD.

Despite mortality being used to measure the effectiveness of treatments, QoL should be an additional target [3-5]. Thus, QoL improvement is commonly considered as a major expectation for elderly patients' profile after TAVI [3-5, 27, 28]. Amelioration of QoL after TAVI may be more beneficial than observed after surgical treatment of severe AS, even including less invasive mini-thoracotomy and mini-sternotomy techniques [8]. In our study, no differences between groups in all components of the EQ-5D-3L questionnaire were confirmed. Similar results in VAS change during follow-up were observed in patients with and without history of cardiac surgery with chest opening. However, numerically higher improvement in patients without previous sternotomy might suggest that this result could reach statistical significance with a higher number of included patients.

Most of the limitations are directly related to the non-randomised, observational study design. The decision for suitabil- ity and eligibility for TAVI was conducted by a multidisciplinary local Heart Team according to current guidelines, although potential bias in patients and treatment selection could affect the outcomes. Thus, these results should be considered as hypothesis-generating rather than causative. There are also limitations related to the instrument for QoL evaluation. EQ-5D-3L is a generic questionnaire with a low sensitivity. Furthermore, no disease-specific QoL tool was used due to time-consuming evaluation. CABG was the reason for previous cardiac surgery in most of the patients. In the remaining six patients ( $17.6 \%$ of this group) the indication for previous cardiac surgery with sternotomy was not documented. Furthermore, the interval between previous chest opening and TAVI was unknown.

In conclusion, TAVI seems to be a safe and effective technique for the treatment of severe AS in patients with previous cardiac surgery with sternotomy. Similar complication rates and QoL outcomes were observed regardless of the status of previous cardiac operations. This observation might lead the Heart Team to consider TAVI as an attractive option in the population of high-risk patients with AS and previous sternotomy.

\section{Conflict of interest: none declared}

\section{References}

1. Gilard M, Eltchaninoff H, Lung B, et al. FRANCE 2 Investigators. Registry of Transcatheter Aortic-Valve Implantation in High-Risk Patients. N Engl J Med. 2012; 366(18): 1705-1715, doi: 10.1056/nejmoa1114705.

2. Reardon MJ, Van Mieghem NM, Popma JJ, et al. SURTAVI Investigators. Surgical or Transcatheter Aortic-Valve Replacement in Intermediate-Risk Patients. N Engl J Med. 2017; 376(14): 1321-1331, doi: 10.1056/NEJMoa1700456, indexed in Pubmed: 28304219 .

3. Tokarek T, Sobczyński R, Dziewierz A, et al. Clinical outcomes in patients after surgical and transcatheter aortic valve replacement. Pol Arch Med Wewn. 2015; 125(10): 755-764, indexed in Pubmed: 26397310.

4. Arnold SV, Spertus JA, Vemulapalli S, et al. Quality-of-Life Outcomes After Transcatheter Aortic Valve Replacement in an Unselected Population: A Report From the STS/ACC Transcatheter Valve Therapy Registry. JAMA Cardiol. 2017; 2(4): 409-416, doi: 10.1001/jamacardio.2016.5302, indexed in Pubmed:28146260.

5. Lange R, Beckmann A, Neumann T, et al. Quality of Life After Transcatheter Aortic Valve Replacement. Prospective Data From GARY (German Aortic Valve Registry). JACC: Cardiovascular Interventions. 2016; 9(24): 2541-2554, doi: 10.1016/ j.jcin.2016.09.050.

6. Kleczyński P, Bagieński M, Sorysz D, et al. Short- and intermediate-term improvement of patient quality of life after transcatheter aortic valve implantation: a single-centre study. Kardiol Pol. 2014; 72(7): 612-616, doi: 10.5603/KP.a2014.0065, indexed in Pubmed: 24671914

7. Bagienski M, Kleczynski P, Dziewierz A, et al. Early- and mid-term outcomes after transcatheter aortic valve implantation. Data from a single-center registry. Adv Interv Cardiol. 2016; 12(2): 122-127, doi: 10.5114/aic.2016.59362, indexed in Pubmed: 27279871. 
8. Tokarek T, Siudak Z, Dziewierz A, et al. Assessment of quality of life in patients after surgical and transcatheter aortic valve replacement. Catheter Cardiovasc Interv. 2016; 88(3): E80-E88, doi: 10.1002/ccd.26400, indexed in Pubmed: 26800644.

9. Anderson RP. First publications from the Society of Thoracic Surgeons National Database. Ann Thorac Surg. 1994; 57(1): 6-7, indexed in Pubmed:8279920.

10. Nashef S, Roques F, Michel P, et al. European system for cardiac operative risk evaluation (EuroSCORE). Eur J Cardiothorac Surg. 1999; 16(1): 9-13, doi: 10.1016/s1010-7940(99)00134-7.

11. Walther T, Blumenstein J, van Linden A, et al. Contemporary management of aortic stenosis: surgical aortic valve replacement remains the gold standard. Heart. 2012; 98 Suppl 4: iv23-iv29, doi: 10.1136/heartjnl-2012-302399, indexed in Pubmed: 23143122.

12. Gillinov A, Casselman F, Lytle B, et al. Injury to a patent left internal thoracic artery graft at coronary reoperation. Ann Thorac Surg. 1999; 67(2): 382-386, doi: 10.1016/s0003-4975(99)00009-0.

13. Ando T, Briasoulis A, Holmes AA, et al. Transcatheter aortic valve replacement versus surgical aortic valve replacement in patients with previous coronary artery bypass surgery: a systematic review and meta-analysis. Int J Cardiol. 2016; 215: 14-19, doi: 10.1016 j.ijcard.2016.04.033, indexed in Pubmed: 27104920.

14. Kleczyński P, Bagieński M, Dziewierz A, et al. Twelve-month quality of life improvement and all-cause mortality in elderly patients undergoing transcatheter aortic valve replacement. Int J Artif Organs. 2016; 39(8): 444-449, doi: 10.5301/ijao.5000521, indexed in Pubmed: 27716868.

15. Kappetein AP, Head SJ, Généreux P, et al. Updated standardized endpoint definitions for transcatheter aortic valve implantation: the Valve Academic Research Consortium-2 consensus document. EuroIntervention. 2012; 8(7): 782-795, doi: 10.4244/ EIJV8I7A121, indexed in Pubmed: 23022744.

16. Bajaj A, Sethi A, Rathor P, et al. Impact of previous cardiac surgery on patients undergoing transcatheter aortic valve implantation: A meta-analysis. Heart Lung. 2016; 45(4): 350-358, doi: 10.1016/j.hrtlng.2016.04.002, indexed in Pubmed: 27157867.

17. D'Onofrio A, Rubino P, Fusari M, et al. Impact of previous cardiac operations on patients undergoing transapical aortic valve implantation: results from the Italian Registry of Transapical Aortic Valve Implantation. Eur J Cardiothorac Surg. 2012; 42(3): 480485, doi: 10.1093/ejcts/ezs027, indexed in Pubmed: 22351707.

18. Walther T, Falk V, Borger MA, et al. Transapical aortic valve implantation in patients requiring redo surgery. Eur J Cardiothorac Surg. 2009; 36(2): 231-4; discussion 234, doi: 10.1016/j. ejcts.2009.02.016, indexed in Pubmed: 19324566.
19. Leshem-Rubinow E, Abramowitz Y, Steinvil A, et al. Outcomes of Transfemoral Transcatheter Aortic Valve Implantation in Patients With Previous Coronary Bypass. Am JCardiol. 2015; 116(3): 431-435, doi: 10.1016/..amjcard.2015.04.055, indexed in Pubmed: 26054290.

20. Minha S, Magalhaes MA, Barbash IM, et al. Impact of previous coronary artery bypass grafting on patients undergoing transcatheter aortic valve implantation for aortic stenosis. Am J Cardiol. 2014; 113(7): 1222-1227, doi: 10.1016/j.amjcard.2013.12.029, indexed in Pubmed: 24513466.

21. Castellant P, Didier R, Bezon E, et al. Comparison of Outcome of Transcatheter Aortic Valve Implantation With Versus Without Previous Coronary Artery Bypass Grafting (from the FRANCE 2 Registry). Am J Cardiol. 2015; 116(3): 420-425, doi: 10.1016/j. amjcard.2015.04.057, indexed in Pubmed:26071993.

22. Ducrocq G, Al-Attar N, Himbert D, et al. Early and mid-term outcomes in patients undergoing transcatheter aortic valve implantation after previous coronary artery bypass grafting. Eur J Cardiothorac Surg. 2012; 41(3): 499-504, doi: 10.1093/ejcts/ezr041, indexed in Pubmed: 22345175.

23. Drews T, Pasic M, Buz S, et al. Transapical aortic valve implantation after previous heart surgery. Eur J Cardiothorac Surg. 2011; 39(5): 625-630, doi: 10.1016/j.ejcts.2010.06.023, indexed in Pubmed: 20691604.

24. Webb JG, Wood DA, Ye J, et al. Transcatheter valve-in-valve implantation for failed bioprosthetic heart valves. Circulation. 2010; 121(16): 1848-1857, doi: 10.1161/CIRCULATIONAHA.109.924613, indexed in Pubmed: 20385927.

25. Papadopoulos N, Ilioska P, Fichtlscherer S, et al. Transapical aortic valve implantation in patients with previous cardiac surgery. Ann Thorac Surg. 2014; 97(1): 37-42, doi: 10.1016/j. athoracsur.2013.07.077, indexed in Pubmed: 24075497.

26. Adams DH, Popma JJ, Reardon MJ, et al. U.S. CoreValve Clinical Investigators. Transcatheter aortic-valve replacement with a self-expanding prosthesis. N Engl J Med. 2014; 370(19): 1790-1798, doi: 10.1056/NEJMoa1400590, indexed in Pubmed: 24678937.

27. Bagienski M, Tokarek T, Wiktorowicz A, et al. Sex-related differences in clinical outcomes and quality of life after transcatheter aortic valve implantation for severe aortic stenosis. Adv Interv Cardiol. 2017; 13(3): 233-239, doi: 10.5114/aic.2017.70195, indexed in Pubmed: 29056996.

28. Olszewska K, Tokarek T, Bętkowska-Korpała B, et al. Assessment of cognitive functions and quality of life in patients scheduled for transcatheter aortic valve implantation: a pilot study. Adv Interv Cardiol. 2017; 13(3): 258-262, doi: 10.5114/aic.2017.70199, indexed in Pubmed: 29056999.

Cite this article as: Tokarek T, Dziewierz A, Bagienski M, et al. Impact of previous cardiac surgery with sternotomy on clinical outcomes and quality of life after transcatheter aortic valve implantation for severe aortic stenosis. Kardiol Pol. 2018; 76(5): 838-844, doi: 10.5603/KP.a2018.0028. 